\title{
A Taxonomy for the Social Agents of Scientific Change
}

\author{
Nicholas Overgaard \\ IHPST, University of Toronto \\ nicholas.overgaard@mail.utoronto.ca
}

An earlier version of this paper was awarded the 2015 IHPST Award for the Best Essay on the Theory of Scientific Change.

\section{Keywords}

theoretical scientonomy, social agents of scientific change, group, accidental group, community, epistemic community, non-epistemic community, scientific community, pseudoscientific community

\section{Abstract}

Although we accept that a scientific mosaic is a set of theories and methods accepted and employed by a scientific community, scientific community currently lacks a proper definition in scientonomy. In this paper, I will outline a basic taxonomy for the bearers of a mosaic, i.e. the social agents of scientific change. I begin by differentiating between accidental group and community through the respective absence and presence of a collective intentionality. I then identify two subtypes of community: the epistemic community that has a collective intentionality to know the world, and the non-epistemic community that does not have such a collective intentionality. I note that both epistemic and non-epistemic communities might bear mosaics, but that epistemic communities are the intended social agents of scientific change because their main collective intentionality is to know the world and, in effect, to change their mosaics. I conclude my paper by arguing we are not currently in a position to properly define scientific community per se because of the risk of confusing pseudoscientific communities with scientific communities. However, I propose that we can for now rely on the definition of epistemic community as the proper social agent of scientific change. 


\section{Introduction}

As theoretical scientonomists, we focus our analyses on different scientific mosaics. Similarly, we hold that every mosaic is the product of a social agent of scientific change, the scientific community. In fact, the notion of scientific community is implicit in our definition of scientific mosaic: a mosaic is a set of theories and methods accepted and employed by a scientific community (Barseghyan, 2015, p. 43). Yet, apart from a hesitant definition of scientific community as "the bearer of a scientific mosaic" in the "Open Questions" section of The Laws of Scientific Change (Barseghyan, 2015, p. 249), we currently have no concrete understanding of what a scientific community actually is, let alone a definition for community.

This paper initiates the process of understanding scientific communities in a scientonomic context by outlining a basic taxonomy for the social agents of scientific change. Part of this paper's purpose is to fill a current void in the field, giving scientonomists a set of basic concepts which they can then use and elaborate. Another part of its purpose is to refine the scope of scientonomy so as to exclude social agents like businesses and governments that, at least in principle, are not intended objects of scientonomic study. To achieve these goals, I will provide grounds for differentiating between mere accidental groups that happen to share a certain characteristic and actual communities that purposely share a collective goal. After clearly defining community, I will describe what I call epistemic community, so as to distinguish communities aiming at knowing the world from those not pursuing such an aim. Finally, I will briefly note that the task of defining scientific community in particular is difficult at the moment, and therefore a task for another paper.

\section{Social Ontology}

It is obvious that we can define the social agents of scientific change, be it scientific communities or epistemic communities, according to a variety of criteria. The ultimate goal of any good taxonomy is to serve the main task of the discipline - in this case, the task of analyzing how science changes over time. To that end, I will, where possible, rely on the findings of social ontology (Tollefsen, 2014; Lawson, 2014; Searle, 2006; Tuomela, 2002). But before proposing this taxonomy, one might ask, why favour a social ontological perspective?

What interests social ontologists about the social realm is its reality or existence - the ontological. As of yet, social ontologists have not systematically analyzed scientific communities as distinct social agents. Social ontologists have largely guided their efforts towards better understanding, for instance, economic institutions (Pratten, 2014). But the findings of their field can also be applied to scientific communities. I suggest that adopting a social ontological perspective of communities - scientific or other - is useful in at least two important ways.

First, social ontology is a selective, yet generalizable theory of the social. It is selective in the sense that social ontologists do not consider every social phenomenon to exist. Rather, they propose particular concepts to clarify the difference between accidental groups of individuals with a shared characteristic, and communities that assemble for a collective purpose. The selectivity of social ontology guides a researcher of communities away from the endless path of defining and redefining scientific community at the start of each new project, and instead offers the hope of an accepted definition. Additionally, social ontology is generalizable in the sense that it uses clearly defined concepts applicable to different historical contexts. In practice, social ontology allows a researcher to properly situate her theoretical accounts of scientific change in the appropriate historical context. This is a response to what Peter Galison calls the problem of Relentless Historicism (Galison, 2008, pp. 122-123) and what we call the particularism vs. generalism debate (Barseghyan, 2015, pp. 81-82).

Second, social ontologists argue that all communities - scientific or not - have agentive functions, for the ontological aspect of social ontology requires a social entity to be capable of effecting change. In other words, social ontologists hold that communities are not merely passive objects of study, but active bodies in the natural world. In the case of scientific communities, social ontologists would hold that they actively engage in the production of knowledge.

It also worth emphasizing that an ontological approach to scientific communities shifts our perspective on the producers of scientific knowledge from the individual level to the social, as is the accepted in scientonomy 
(Barseghyan, 2015, pp. 43-52). Conversely, current historical case studies tend to focus on exceptional individuals in science: the Galileos, the Newtons, the Einsteins. This is understandable, since individual actors are relatively easy to identify. In order to eventually study the actual agents of scientific change - communities - scientonomists need to first be able to identify these communities. With a unified taxonomy of scientific communities, scientonomists will be better equipped to focus on the social level of analysis.

\section{Accidental Group and Community}

Let's start our definitions from the most abstract of our concepts, that of group. We can define group as "two or more people who share any characteristic":

\section{Group $\equiv$}

Two or more people who share any characteristic.

Groups can be of two major types. There are groups which have a collective intentionality, i.e. share collective goals, and there are groups which don't have any collective intentionality (cf. Searle, 2006, p. 16). A group that has a certain collective intentionality is a community. In contrast, a group that does not have any collective intentionality is a mere accidental group. Here is the basic taxonomy:

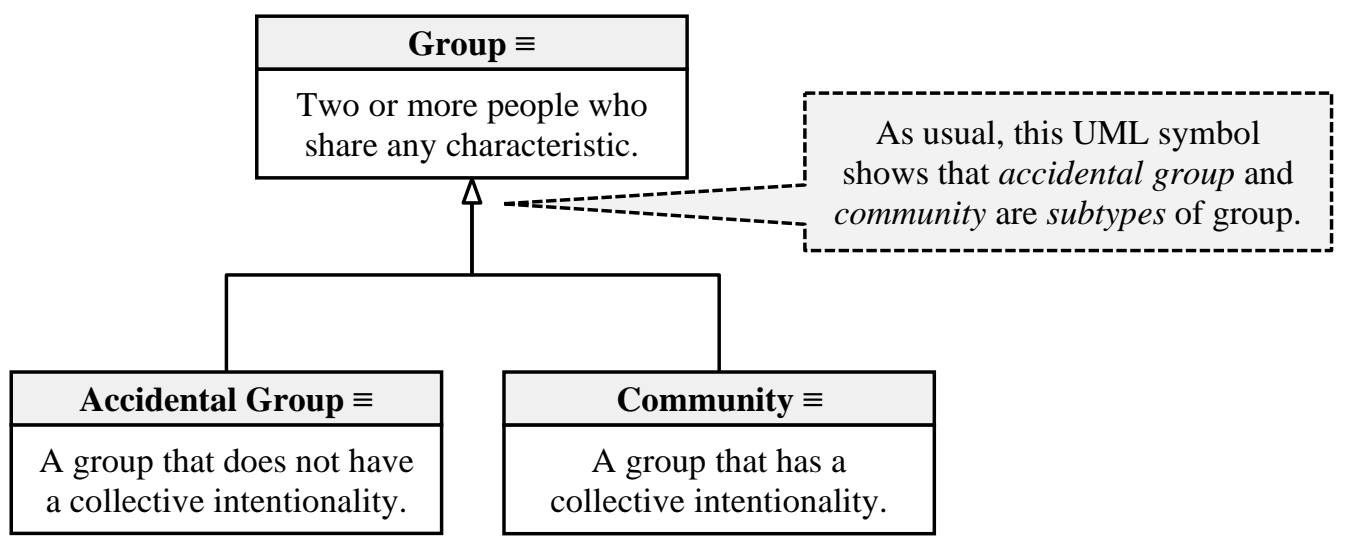

How does collective intentionality help to distinguish communities from accidental groups? In simple terms, collective intentionality is the presence of a collective goal which helps a community act as a unified group. For example, a professional football team forms a community, since they share the goal of trying to outscore the opposing team. In contrast, an accidental group only happens to share some characteristics. All left-handed Armenian smokers would be an accidental group. The same applies to the accidental group of all mothers, or all football players.

Admittedly, any group has the potential to jointly pursue a collective goal. For example, a group of strangers at the park can conceivably assemble to play a game of football without any initial plan or intention of doing so. But having the potential to pursue a goal is not the same as actually having that collective goal. Until the point that that group jointly pursues the collective goal of playing football, they are not considered a community. In principle, some set of indicators will help distinguish actually having collective goals from potentially having collective goals: perhaps a community of football players organized the game ahead of time, booked a field for playing, and divided its members into opposing teams, whereas the group without the collective goal to jointly play a football game would have done no such actions for it had no such actual goal to play football. That said, the collective goal of a community need not be pursued at all times; a community remains a community even when not actively pursuing its goal. The goal of a football team is to score points and to win games and competitions, but the team is not necessarily always engaged in pursuing this goal. A football team remains a 
football team both on the field and in the locker room; it need not be in the midst of playing football to be considered a community. What matters to distinguish a football team as a community from a group with the potential to become a football team is that there is an actual collective goal in the former case.

Furthermore, parts within the same community can be carrying out different actions. These actions, so long as they are the actions of a single community, are in turn oriented towards some collective goal. To continue with the example of a football team, it consists of players who play different positions. Each position has particular tasks that differ from one another, like passing the ball to a free teammate, or getting the ball back from an opponent. In combination, these distinct tasks are intended in pursuit of a collective goal, to outscore the opposing team. Each part of a community can act in coordination with another part of the same community in pursuit of a collective goal. This phenomenon of jointly pursuing a common goal through distinct actions is expressed through what we call authority delegation (Overgaard \& Loiselle, 2016).

The key role of collective intentionality, or the joint pursuit of a collective goal, becomes especially apparent in its absence. Without collective intentionality, a group is accidental: disorganized, disunited, and incapable of acting as a cohesive body. Our experience tells us, however, that human beings do carry out collective action in much more than random or chance coordination. A football team is different from a mere group of people chaotically kicking and throwing the ball in that the team cooperates to outscore the opposing team; an orchestra is different from a mere group of people making random noises in that the orchestra cooperates to collectively perform a piece of music; a government is different from a society in which every person is for themselves in that the government operates with a collective intentionality to serve its citizens, as indicated in part through its laws, hospitals, and police forces. We know collective intentionality is part of the social world because we can identify goal-seeking, cooperating communities in our world. To deny the existence of collective intentionality is to accept total social anarchy and chance-based cooperation - too much of a coincidence, considering the examples listed above.

Lastly, let us also appreciate that communities can consist of other communities. For example, we can treat the University of Toronto as its own community. Within the University of Toronto, we have the sub-community of the Institute for the History and Philosophy of Science (IHPST). The IHPST, in turn, has its own subcommunity of scientonomists. Each sub-community is a part of the same overarching community, i.e. scientonomists are part of the IHPST, as well as part of the University of Toronto, but also has its own distinct collective intentionality. If part of a community has its own collective intentionality, then by definition, it is also a community. The following diagram describes such a situation:

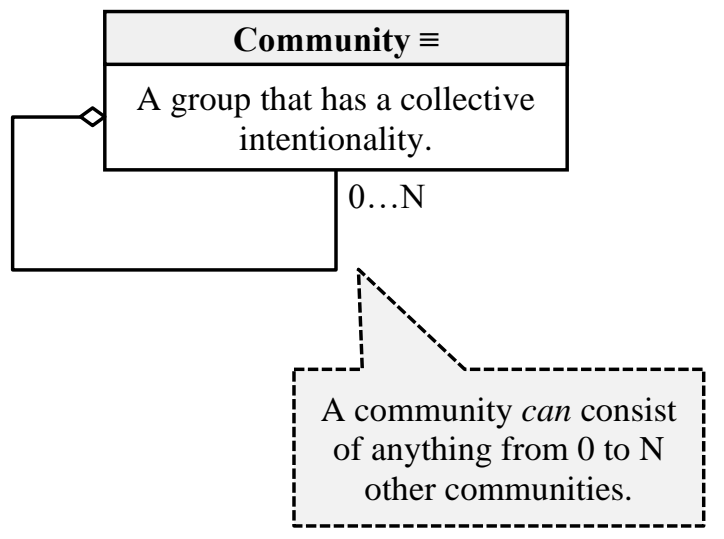

Naturally, not all communities have sub-communities. We can easily conceive of a community that doesn't have sub-communities: returning to the examples of sub-communities from above, the community of scientonomists is, at least at the moment, not further divisible into sub-communities. So it is possible, but not necessary for communities to have sub-communities. 


\section{Epistemic and Non-Epistemic Communities}

Now that we have a basic definition of community, let's proceed towards the notion of epistemic community. An epistemic community can be defined as a community with a collective intentionality to know the world. Similarly, a non-epistemic community can be defined as a community without a collective intentionality to know the world. Here are the definitions of these new concepts:

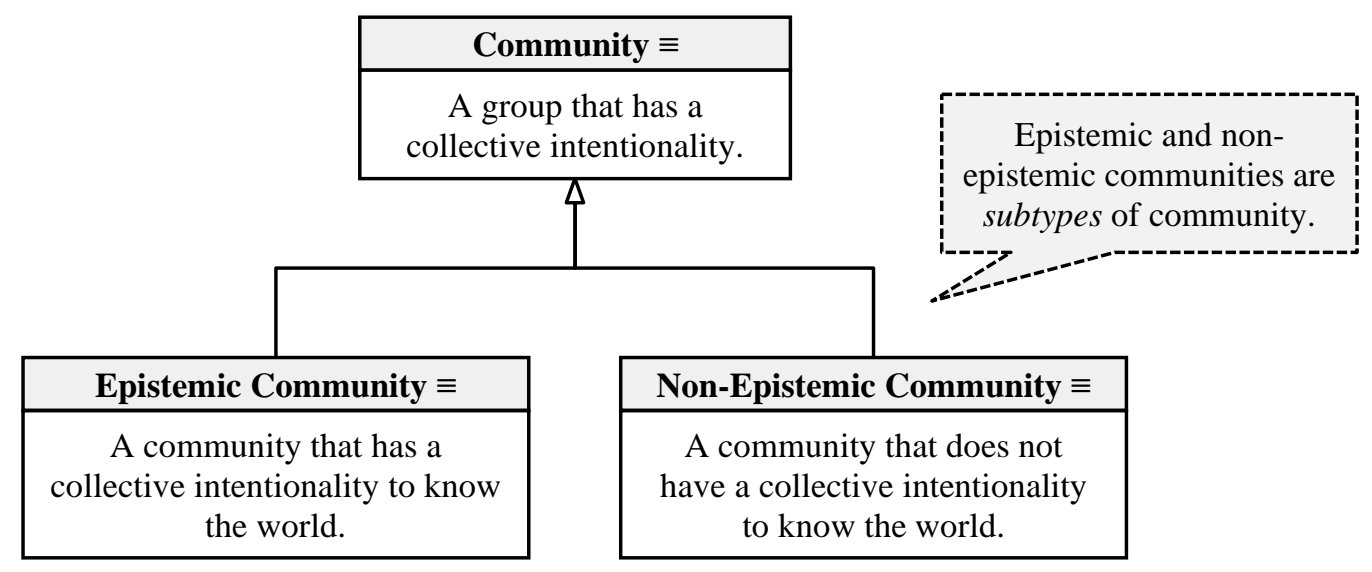

This distinction is important for differentiating between epistemic communities and other types of communities, like political, economic, or familial communities. As an example, it is clear that an orchestra is a community: the various musicians can be said to have a collective intentionality to play a piece of music. Yet, an orchestra cannot be said to have a collective intentionality to know the world. It may, de facto, accept theories about performance technique or instrument maintenance. These theories may even assist in more effectively accomplishing the collective goal of playing a piece of music. However, an orchestra is a non-epistemic community because it lacks a collective intentionality aimed at knowing the world.

Consider another example: the case of a political party. We know that a political party can be considered a community - it clearly has a collective intentionality. A political party will even have a certain mosaic, i.e. a set of accepted theories concerning effective governance, the ideals of society, etc. Yet, a political party would be considered a non-epistemic community because it lacks a collective intentionality to know the world. In short, non-epistemic communities may very well bear their own mosaics, for having a mosaic and being prepared to accept new theories doesn't amount to having a collective intentionality to know the world.

If we accept the distinction between epistemic and non-epistemic communities, there is another question concerning how these types communities might relate to one another: specifically, can an epistemic community be the sub-community of a non-epistemic community? Let's take the example of a business, like Google. We can say that Google is a non-epistemic community, for it does not have a collective intentionality to know the world. Rather, it has a collective intentionality to make profit - the main goal of any business. At the same time, we know that Google is an innovative company, one that probably has a research and development team trying to better know Internet technologies, or a marketing team trying to better know how to reach consumers. Google's research and development or marketing teams are trying to better know some element of the world, and in that sense, would be considered epistemic communities. Yet these teams also operate under Google, a non-epistemic community. So it turns out that it is possible for an epistemic community to be the sub-community of a nonepistemic community. It is even likely the case that non-epistemic communities that seem to have, in part, a collective intentionality to know the world do not actually have that collective intentionality in particular, and that it is instead one of their sub-communities with a collective intentionality to know the world. This is why it is important to suggest that non-epistemic communities can consist of epistemic sub-communities: it helps us understand that some part of a non-epistemic community might have a collective intentionality to know the world, but that that collective intentionality is not the primary collective intentionality of the community. After all, it 
would be a mistake to suggest that Google is an epistemic community because it has a collective intentionality to know, say, the digital world; that would be the collective intentionality of one of its sub-communities.

\section{Scientific and Pseudoscientific Communities}

With our definitions of community and epistemic community in place, we can now briefly discuss the notion of scientific community. In a few words, as scientonomists we are at present not properly prepared to define scientific communities. To appreciate this claim, we need to keep in mind a potentially important distinction between scientific and pseudoscientific communities. It is helpful to think of pseudoscientific communities as those that regard themselves as scientific, but are not regarded by others as scientific. They would include communities of creationists, climate-change deniers, or flat-earth societies. While both scientific and pseudoscientific communities can be said to have collective intentionality to know the world, there might be important differences between the two. For example, a fundamentalist religious community that accepts creationism may have a genuine collective intentionality to know the world, but we would be reluctant to qualify this community as scientific.

On the issue of science vs. pseudoscience, we do currently accept that every mosaic contains certain demarcation criteria as part of an employed method of the time (Barseghyan, 2015, p. 10). But to rely exclusively on the demarcation criteria found within a community's mosaic is unsatisfactory, for every community bearing its own mosaic could essentially dictate its own scientific status. Therefore, if we were to rely on the community's own demarcation criteria between science and pseudoscience, we would drive scientonomic studies into absolute relativism. It may eventually turn out that both scientific and pseudoscientific communities operate according to the same laws of scientific change, in which case we could abandon the distinction between them. Still, until scientonomists identify and accept a universal demarcation criterion that transcends changing scientific mosaics, it is important to allow for such a possible distinction.

So we are not in a position to properly define scientific community at the moment. Instead, I claim that all scientific and pseudoscientific communities have a collective intentionality to know the world, and in turn, that all scientific and pseudoscientific communities fall under the more general concept introduced above: that of epistemic community.

\section{Conclusion}

In summary, I have proposed a new taxonomy for the social agents of scientific change. In the foundation of this taxonomy is the most abstract notion of group, which denotes two or more people who share any characteristic. Group has two subtypes - accidental group and community; communities are characterized by the presence of collective intentionality, while accidental groups don't have any collective intentionality. Additionally, I have proposed the notion of epistemic community as a community with a collective intentionality to know the world. It is epistemic communities that bear mosaics and are of primary interest to scientonomists. I have also pointed out that non-epistemic communities (such as corporations) can also consist of epistemic communities. Finally, it is worth emphasizing that we aren't yet in a position to give scientific community a proper scientonomic definition; that is a task for future research.

\section{Suggested Modifications}

Thus, I suggest the following modifications:

\section{[Sciento-2017-0012]}

Accept the following taxonomy of group, accidental group, and community:

- Group $\equiv$ two or more people who share any characteristic.

- Accidental Group $\equiv$ a group that does not have a collective intentionality.

- Community $\equiv$ a group that has a collective intentionality. 


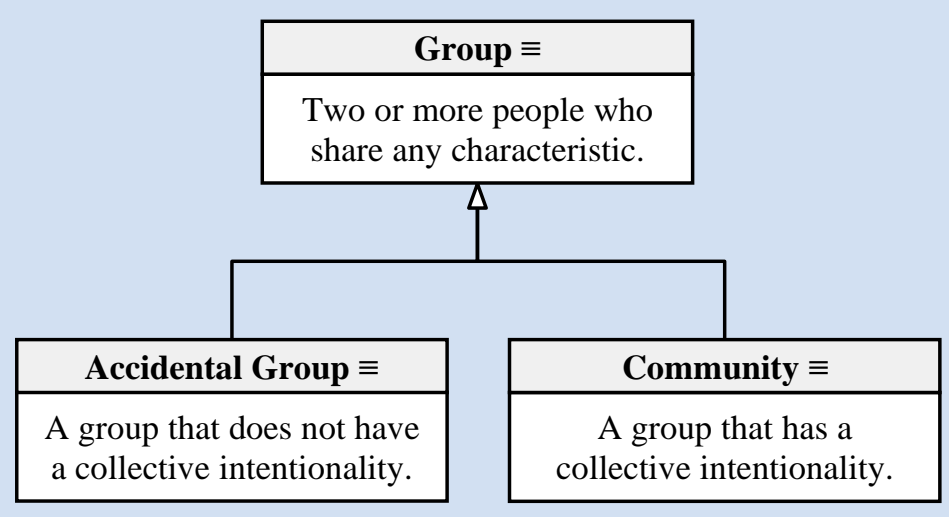

\section{[Sciento-2017-0013]}

Provided that the preceding modification [Sciento-2017-0012] is accepted, accept that communities can consist of other communities.

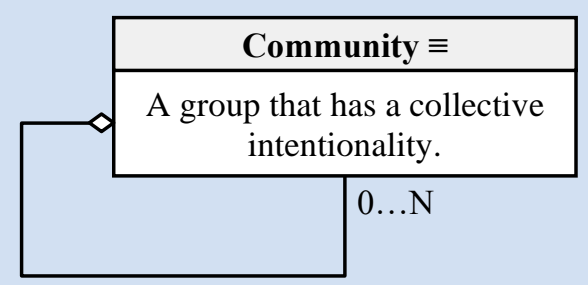

\section{[Sciento-2017-0014]}

Provided that modification [Sciento-2017-0012] is accepted, accept the following definitions of epistemic community and non-epistemic community as subtypes of community:

- Epistemic Community $\equiv$ a community that has a collective intentionality to know the world.

- Non-Epistemic Community $\equiv$ a community that does not have a collective intentionality to know the world.

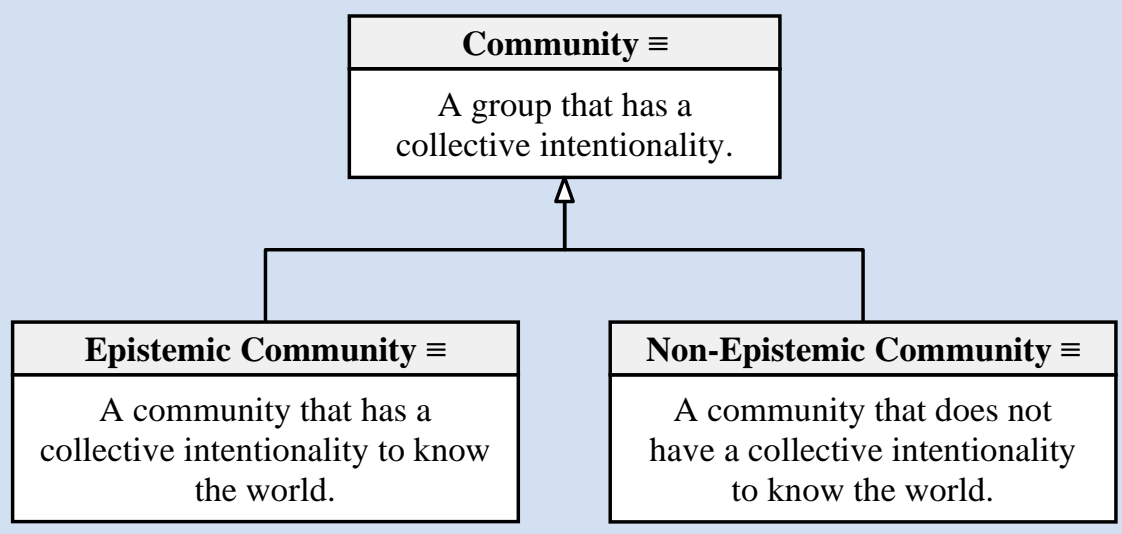

\section{[Sciento-2017-0015]}

Provided that modifications [Sciento-2017-0013] and [Sciento-2017-0014] are accepted, accept that a nonepistemic community can consist of epistemic communities. 


\section{References}

Barseghyan, H. (2015). The Laws of Scientific Change. Springer.

Cartwright, N. \& Montuschi, E. (Eds.) (2014). Philosophy of Social Science: A New Introduction. Oxford University Press.

Galison, P. (2008). Ten Problems in History and Philosophy of Science. Isis 99(1), pp. 111-124.

Lawson, T. (2014). A Conception of Social Ontology. In Pratten (Ed.) (2014), pp. 19-52.

Overgaard, N. \& Loiselle, M. (2016). Authority Delegation. Scientonomy 1, pp. 11-18. Retrieved from http://www.scientojournal.com/index.php/scientonomy/article/view/27065.

Pratten, S. (Ed.) (2014). Social Ontology and Modern Economics. Routledge.

Searle, J. (2006). Social Ontology: Some Basic Principles. Anthropological Theory 6(1), pp. 12-29.

Tollefsen, D. (2014). Social Ontology. In Cartwright \& Montuschi (Eds.) (2014), pp. 85-101.

Tuomela, R. (2002). The Philosophy of Social Practices: A Collective Acceptance View. Cambridge University Press. 